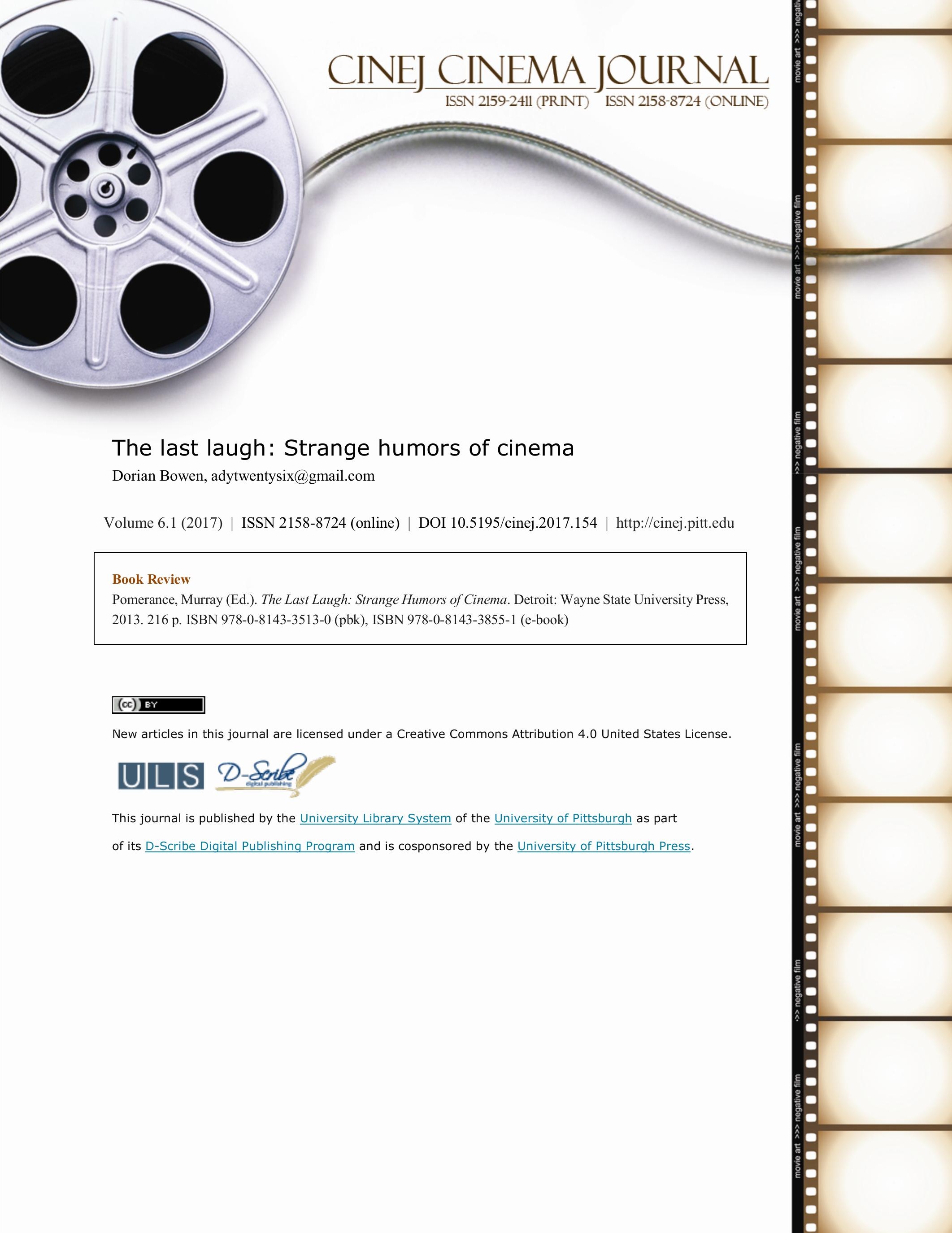




\section{The last laugh: Strange humors of cinema Dorian Bowen}

\section{Why So Serious Funny?}

What is laughter? Many works of film theory examine comedy, both as a genre and a ubiquitous ingredient of storytelling in all its forms- but humans actually resort to laughter in an attempt to express many more emotions than simply enjoyment. The Last Laugh: Strange Humors of Cinema is a compilation of thirteen essays that parse the evidence of these darker psychological undercurrents. Why the characters are depicted onscreen really laughing sometimes, and why do we as spectators respond with laughter to a film, at the specific moments and in the various ways we do?

Gracing the cover of the book is a still frame of Tallullah Bankhead laughing with abandon in Alfred Hitchcock's Lifeboat (1944). It is this specific moment of profundity within the dramatic context of this specific film that serves as the quintessential example of strange humor, for its possession of 'elements of pungency, dramatic weight, sharpness of expression, and personal character' (p. 6). What follows are analyses that span the silent film era to modern day, from specific performances (Conrad Veidt in 1928's The Man Who Laughs) to themes recurrent in a director's catalog (Orson Welles) to entire genres (noir, science fiction/horror, avant-garde, gangster) to specific films, including Don't Look Now (1973), Black Swan (2010), Henry Fool (1997), The Treasure of the Sierra Madre (1948), The Dark Knight (2008), and A.I. Artificial Intelligence (2001). There are many answers to the hypothesis of what ends up inspiring dark laughter but they are all complex and contradictory. Despite how often we like to think laughter is pleasant, it is frequently an instinctive response to discomfort or irony or surprise. It can be an exhibition of power as often as a cathartic release at the point of utter hopelessness. 
Pomerance prefaces the compilation with the disclaimer 'A definitive statement is beyond the scope of a single volume, and a collection is especially prone to vagaries of individual interpretations and personal choices of material' (p.6). Some scholars may wish to have seen certain genres explored in more depth or lament that certain films had to be omitted, but I believe most will find this admirable breadth of scope to be entirely satisfying. In this study consideration is given to classic studio films, independents, found-footage montages, modern blockbusters, and even unreleased films (an entire essay is devoted to the stunning plot of Jerry Lewis' The Day the Clown Cried). As are many points of views represented- not just of the characters and contemporary audiences, but to the changing perspectives over time of critics and viewers, to the authors and screenwriters, to the whimsy of directors and their behind-the-scenes technical approaches, and even to the experience of characters that are not human at all.

Each contributor lends a voice in support of film theory reconsidering our canonized definitions of and associations with humor. Physical slapstick and intellectual wit may be the beginning of comedy but they are by no means the end. Reconciling how, for example, one generation rejects a genre as falling short of the classical standards of filmmaking, while another embraces its self-consciousness as a sign of higher achievement, benefits from looking more closely at the nuance of humor and its effects on our senses of propriety, artistic expectations and societal norms. In fact somehow the process of exploring dark humors results in a light-hearted reversal of expectations of what is drama and what is comedy, what is real and what is not... and therefore what is as we initially thought it was and what is awaiting an entirely new cinematic interpretation. 
Dorian Bowen

Living Computers: Museum + Labs

22451 st Ave S

Seattle, WA 98134

dorianbo@vulcan.com

206-342-2165 